\title{
Application of genotypic and phenotypic analyses to commercial probiotic strain identity and relatedness
}

\author{
P.S.M. Yeung ${ }^{1}$, C.L. Kitts ${ }^{2}$, R. Cano ${ }^{2}$, P.S. Tong ${ }^{1}$ and M.E. Sanders ${ }^{1}$ \\ ${ }^{1}$ Dairy Products Technology Center, California Polytechnic State University, San Luis Obispo, CA, USA, and ${ }^{2}$ Environmental \\ Biotechnology Institute, California Polytechnic State University, San Luis Obispo, CA, USA
}

\section{ABSTRACT}

Aims: The objective of this study was to generate strain-specific genomic patterns of a bank of 67 commercial and reference probiotic strains, with a focus on probiotic lactobacilli.

Methods and Results: Pulsed-field gel electrophoresis (PFGE) was used as the primary method for strain differentiation. This method was compared with carbohydrate fermentation analysis. To supplement visual comparison, PFGE patterns were analysed quantitatively by cluster analysis using unweighted pair group method with arithmetic averages. $S m a \mathrm{I}, N o t \mathrm{I}$ and $X b a \mathrm{I}$ were found to effectively generate clear and easy-to-interpret PFGE patterns of a range of probiotic strains. Some probiotic strains from different sources shared highly similar PFGE patterns.

Conclusions: Results document the value of genotypic strain identification methods, combined with phenotypic methods, for determining probiotic strain identity and relatedness. No correlation was found between relatedness determined by carbohydrate fermentation profiles alone compared with PFGE analysis alone. Some commercial strains are probably derived from similar sources.

Significance and Impact of the Study: This approach is valuable to the probiotic industry to develop commercial strain identification patterns, to provide quality control of strain manufacturing production runs, to track use of protected strains and to determine the relatedness among different research and commercial probiotic strains.

Keywords: Bifidobacterium, Lactobacillus, probiotics, pulsed-field gel electrophoresis, strain differentiation.

\section{INTRODUCTION}

The increasing application of probiotics in food products and dietary supplements underscores the need to properly identify these beneficial bacteria. Probiotics are live microorganisms which when administered in adequate amounts confer health benefits to the host (FAO/WHO 2001; ftp.fao.org/es/ESN/food/foodandfood_probio_en.stm). Probiotic activities, which confer human health benefits (such as modulating immune system function, reducing host colonization by pathogens and enhancing lactose digestion in lactose maldigesters), have been reviewed (Schiffrin and Blum 2001; Marteau et al. 2002). Previous studies have indicated that certain probiotic activities are strain-specific (Lee et al. 1993; Gupta et al. 1996; Jacobsen et al. 1999) and thus, identification of probiotics to the strain level is necessary. This conclusion is supported by $\mathrm{FAO} / \mathrm{WHO}$ guidelines (http://www.fao.org/es/ESN/food/foodandfood_ probio_en.stm) for the use of probiotics in food which stipulate that commercial probiotics be identified to the strain level. Further, the ability to identify specific probiotic strains provides manufacturers a useful quality control 
tool and enables strains fed as probiotics to be tracked for efficacy and safety purposes. Strain identification also aids in surveillance and epidemiological studies (Rautio et al. 1999).

Current strain-specific techniques used for probiotics comprise multiple DNA-based methods such as pulsed-field gel electrophoresis (PFGE), random amplified polymorphic DNA (RAPD) PCR, ribotyping and protein-based methods such as SDS-PAGE. The available literature indicates that for many genera, PFGE is more effective than ribotyping, SDS-PAGE or RAPD-PCR in discriminating between strains (O'Riordan and Fitzgerald 1997). Based on accumulating evidence from previous studies, PFGE is considered best for strain identification because of its sensitivity, consistency and accuracy.

The PFGE is a strain-specific DNA typing method that has been used widely for genomic analysis of various micro-organisms. This method has been used to differentiate members of different genera including Lactococcus (Tanskanen et al. 1990), Clostridia (Hielm et al. 1998), and Streptomyces (Leblond et al. 1990), and is considered to be a discriminating and reproducible method to differentiate strains of intestinal bacteria (O'Sullivan 1999). PFGE has been used in strain-typing of lactobacilli and bifidobacteria. Bourget et al. (1993) used this technique to compare the genomic restriction patterns of five Bifidobacterium breve strains. It has also been used for strain differentiation and chromosome size estimation in Lactobacillus acidophilus (Roussel et al. 1993; Sanders et al. 1996), L. plantarum (Daniel 1995), and other lactic acid bacteria (Tanskanen et al. 1990). In our previous study (Yeung et al. 2002), we applied partial 16S rDNA sequencing, carbohydrate fermentation and fatty acid methyl ester (FAME) analyses to determine the species identification of some commercial probiotic strains. In the present study, we continue this line of research by obtaining strain-specific identification of these commercial probiotic strains using PFGE. In addition, strain relatedness apparent from PFGE fingerprints were evaluated by comparing with carbohydrate fermentation profiles as indicators of phenotypic relatedness of tested strains.

\section{MATERIALS AND METHODS}

\section{Bacterial strains and culture conditions}

The bacterial strains used in this study along with their sources are listed in Table 1. All Lactobacillus and Bifidobacterium strains were grown in MRS (Difco Laboratories, Sparks, MD, USA) or deMan, Rogosa and Sharpe (MRS) supplemented with 0.05\% L-cysteine-HCl (Fisher Scientific, Pittsburgh, PA, USA) agars, respectively. All plates inocu- lated with cells were incubated anaerobically in GasPak ${ }^{\circledR}$ System with BBL ${ }^{\circledR}$ GasPak Plus ${ }^{\text {TM }}$ disposable $\mathrm{H}_{2}$ and $\mathrm{CO}_{2}$ generator envelopes (BD Diagnostic Systems, Sparks, MD, USA). Upon receipt of the bacterial strains, frozen stocks (with the addition of glycerol, 10\% final concentration) were immediately prepared from late log-phase cultures and kept at $-80^{\circ} \mathrm{C}$. Prior to every experiment, strains from the frozen stock were subcultured at least once in the appropriate medium. Bacterial cultures from probiotic-containing food products were isolated by streaking the product directly on MRS (for lactobacilli) or MRS supplemented with $0.05 \%$ L-cysteine-HCl (for bifidobacteria) agar and incubated anaerobically for $48 \mathrm{~h}$ at $37^{\circ} \mathrm{C}$ for single strain isolation. Gram stain was carried out on selected colonies to determine the Gram reaction and morphologies. Once purified, frozen stocks were prepared as described above. Species identification used throughout the text was determined in our previous study by partial $16 \mathrm{~S}$ rDNA sequencing or carbohydrate fermentation analysis (Yeung et al. 2002).

\section{DNA extraction}

The in situ preparation of chromosomal DNA for PFGE was modified from the method of Tanskanen et al. (1990). An aliquot of overnight culture was transferred to fresh MRS or MRS and $0.05 \%$ L-cysteine-HCl broth and grown at $37^{\circ} \mathrm{C}$ for $12-16 \mathrm{~h}$. Chloramphenicol was added to a final concentration of $100 \mu \mathrm{g} \mathrm{ml}^{-1}$ and the incubation was continued for $1 \mathrm{~h}$. Cells from 1.5 to $3.0 \mathrm{ml}$ samples of the culture were harvested by centrifugation for $30 \mathrm{~s}$ in a microcentrifuge at $11000 \mathrm{~g}$ and washed with $1 \mathrm{ml}$ of cell

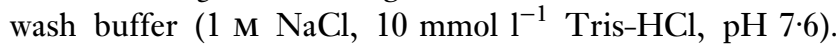
The cell pellets were resuspended in $300 \mu \mathrm{l}$ of the same buffer, warmed to $55^{\circ} \mathrm{C}$ and mixed with $300 \mu \mathrm{l}$ of $2 \%$ (w/v) pulsed-field gel agarose (Sigma, St Louis, MO, USA) in cell wash buffer. The suspension was poured into a CHEF plug mould (Bio-Rad Inc., Hercules, CA, USA) and was allowed to solidify at room temperature for 15$20 \mathrm{~min}$. Cells in the agarose blocks were lysed in situ with $10 \mathrm{ml}$ of lysis buffer $\left(6 \mathrm{mmol}{ }^{-1}\right.$ Tris-HCl, $1 \mathrm{~mol} \mathrm{l}^{-1}$ $\mathrm{NaCl}, 100 \mathrm{mmol}^{-1}$ EDTA, $1 \mathrm{mg} \mathrm{ml}^{-1}$ lysozyme, pH 8.0) and $400 \mathrm{U}$ mutanolysin solution (Sigma) at $37^{\circ} \mathrm{C}$ for $24 \mathrm{~h}$. The reagents were drained and $10 \mathrm{ml}$ of proteinase $\mathrm{K}$ solution [250 mmol $\mathrm{l}^{-1}$ EDTA, pH 8.0, 1\% (w/v) sarkosyl, $100 \mu \mathrm{g} \mathrm{ml}^{-1}$ proteinase $\left.\mathrm{K}\right]$ was added to hydrolyse cellular protein. The blocks were incubated at $50^{\circ} \mathrm{C}$ overnight. Subsequently, the blocks were treated twice for $12 \mathrm{~h}$ with $10 \mathrm{ml}$ of $1 \mathrm{mmol} \mathrm{l}^{-1}$ phenylmethylsulphonyl fluoride in $1 \mathrm{X}$ TE (10 $\mathrm{mmol} \mathrm{l}^{-1}$ Tris-HCl, $\mathrm{pH} \mathrm{8.0,1} \mathrm{mmol} \mathrm{l}^{-1}$ sodium EDTA) at $25^{\circ} \mathrm{C}$. The blocks were washed three times with $10 \mathrm{ml}$ of $1 \mathrm{X} \mathrm{TE}$ for at least $2 \mathrm{~h}$ each at $25^{\circ} \mathrm{C}$, and stored at $4^{\circ} \mathrm{C}$ in storage solution $\left[0.5 \mathrm{~mol} \mathrm{l}^{-1}\right.$ sodium EDTA, $\mathrm{pH} 8 \cdot 0,1 \%(\mathrm{w} / \mathrm{v})$ sarkosyl]. 
Table 1 Bacterial strains used in this study. The species identification used throughout this text is based on a previous study (Yeung et al. 2002). Discrepancies between species identification and designation by product or supplier have been discussed previously

\begin{tabular}{|c|c|c|c|}
\hline $\begin{array}{l}\text { Laboratory } \\
\text { designation }\end{array}$ & Species identification & Designation by product or supplier & Source \\
\hline ATCC 15696 & ND & B. bifidum & ATCC (Manassa, VA, USA) \\
\hline ATCC 15698 & ND & B. breve & ATCC \\
\hline ATCC 15700 & B. breve* & B. breve & ATCC \\
\hline ATCC 15708 & B. longum* ${ }^{*}$ & B. longum & ATCC \\
\hline ATCC 25962 & ND & B. infantis & ATCC \\
\hline ATCC 29521 & ND & B. bifidum & ATCC \\
\hline ATCC 33199 & L. crispatus* & L. gallinarum & ATCC \\
\hline ATCC 33200 & L. johnsonii* & L. johnsonii & ATCC \\
\hline ATCC 33323 & L. gasseri* $^{*}$ & L. gasseri & ATCC \\
\hline ATCC 700396 & L. acidophilus* & L. acidophilus & ATCC \\
\hline DPTC 001 & B. breve* & B. breve R-070 & Institut Rosell Inc. (Montreal, QC, Canada) \\
\hline DPTC 002 & B. lactis* & B. lactis $\mathrm{BB} 12$ & Chr. Hansen, Inc. (Milwaukee, WI, USA) \\
\hline DPTC 003 & B. lactis* & B. longum $\mathrm{BBL}$ & Chr. Hansen \\
\hline DPTC 004 & B. longum* ${ }^{*}$ & B. longum $\mathrm{BB} 46$ & Chr. Hansen \\
\hline DPTC 005 & L. acidophilus* & L. acidophilus $\mathrm{NCFM}^{\circledR}$ & Rhodia Inc. (Madison, WI, USA) \\
\hline DPTC 006 & L. acidophilus* & L. acidophilus $\mathrm{NCFM}^{\circledR}$ & NCSU (Raleigh, NC, USA) \\
\hline DPTC 007 & L. acidophilus* & L. acidophilus PIM703 & Chr. Hansen \\
\hline DPTC 008 & L. acidophilus* & L. acidophilus SBT2062 & $\begin{array}{l}\text { Snow Yogurt }+2 \text { (Snow Brand Milk } \\
\text { Products Co., Ltd, Kawagoe, Japan) }\end{array}$ \\
\hline DPTC 009 & L. crispatus* & L. crispatus $\mathrm{BG} 2 \mathrm{FO} 4$ & NCSU \\
\hline DPTC 017 & L. crispatus* & L. helveticus NCK388 & NCSU \\
\hline DPTC 018 & L. delbrueckii subsp. bulgaricus* & L. lactis San & Chr. Hansen \\
\hline DPTC 019 & L. delbrueckii subsp. bulgaricus* & L. delbrueckii subsp. bulgaricus MR120 & Rhodia \\
\hline DPTC 020 & L. delbrueckii subsp. bulgaricus* & L. delbrueckii subsp. bulgaricus 2038 & $\begin{array}{l}\text { Yogurt (Meiji Milk Products Co. Ltd, } \\
\text { Tokyo, Japan) }\end{array}$ \\
\hline DPTC 021 & L. delbrueckii subsp. bulgaricus* & L. delbrueckii subsp. bulgaricus 2038 & Yogurt (Meiji Milk Products) \\
\hline DPTC 022 & L. delbrueckii subsp. bulgaricus* & L. delbrueckii subsp. bulgaricus PIM695 & Chr. Hansen \\
\hline DPTC 023 & L. delbrueckii subsp. bulgaricus* & & Snow Yogurt +2 (Snow Brand) \\
\hline DPTC 024 & L. delbrueckii subsp. bulgaricus* & & Snow Yogurt +2 (Snow Brand) \\
\hline DPTC 025 & L. gasseri* & B. breve, B. bifidum or L. acidophilus & Mil Mil fermented milk (Yakult, Tokyo, Japan) \\
\hline DPTC 026 & L. gasseri* & L. gasseri $\mathrm{ADH}$ & NCSU \\
\hline DPTC 027 & L. gasseri* & L. acidophilus DDS-1 & $\begin{array}{l}\text { Capsule supplement (Natren Inc., } \\
\text { Westlake Village, CA, USA) }\end{array}$ \\
\hline DPTC 028 & L. johnsonii* & L. johnsonii 11088 (NCK 088) & NCSU \\
\hline DPTC 029 & L. johnsonii* & L. johnsonii La-1 & Nestlé (Lausanne, Switzerland) \\
\hline DPTC 030 & L. paracase $i^{*}$ & L. casei Shirota & Health drink produced by Yakult \\
\hline DPTC 031 & L. paracasei* & L. jugurti & ACE fermented milk drink (Snow Brand) \\
\hline DPTC 032 & L. paracasei* & L. jugurti & ACE fermented milk drink (Snow Brand) \\
\hline
\end{tabular}


Table 1 (Contd)

\begin{tabular}{|c|c|c|c|}
\hline $\begin{array}{l}\text { Laboratory } \\
\text { designation }\end{array}$ & Species identification & Designation by product or supplier & Source \\
\hline DPTC 033 & L. paracasei* & L. casei & Joie fermented milk drink (Yakult) \\
\hline DPTC 035 & L. paracasei* & L. casei PIM661 & Chr. Hansen \\
\hline DPTC 036 & L. paracasei* & Unknown & Rolly fermented milk (Snow Brand) \\
\hline DPTC 037 & L. reuteri* & L. reuteri $1063-\mathrm{S}$ & Biogaia Biologics (Stockholm, Sweden) \\
\hline DPTC 039 & L. reuteri* & L. reuteri $\mathrm{SD} 2112$ & Biogaia Biologics \\
\hline DPTC 040 & L. reuteri* & L. reuteri $\mathrm{T}-1$ & Biogaia Biologics \\
\hline DPTC 042 & L. rhamnosus* & L. rhamnosus GR-1 & UWO (London, ON, Canada) \\
\hline DPTC 043 & L. rhamnosus* & L. rhamnosus $\mathrm{R}-011$ & Institut Rosell \\
\hline DPTC 044 & L. rhamnosus* & L. rhamnosus $\mathrm{R}-049$ & Institut Rosell \\
\hline DPTC 045 & L. rhamnosus* & L. fermentum RC-14 & UWO \\
\hline DPTC 049 & L. acidophilus $\dagger$ & $\begin{array}{l}\text { B. breve, B. bifidum } \\
\text { or L. acidophilous }\end{array}$ & Mil Mil fermented milk drink (Yakult) \\
\hline DPTC 050 & L. helvaticus $\dagger$ & L. acidophilus PIM883 & Chr. Hansen \\
\hline DPTC 052 & ND & B. longum BB536 & $\begin{array}{l}\text { Lyophilized BB536 (Morinaga } \\
\text { Milk Industries, Zama-City, Japan) }\end{array}$ \\
\hline
\end{tabular}

ND, Species not determined.

* Species determined by partial $16 \mathrm{~S}$ rDNA sequencing (Yeung et al. 2002).

$\dagger$ Species determined by carbohydrate fermentation as sequencing data were unavailable (Yeung et al. 2002).

¥Strains sourced from North Carolina State University (NCSU), University of Western Ontario (UWO), Chr. Hansen, Inc., Rhodia Inc., Institute Rosell, Nestlé, Oregon State University, Biogaia Biologics, Northeast Nutraceuticals (NN) and ATCC were obtained directly from source. All other strains were isolated from retail products.

\section{Restriction digestion}

The agarose blocks were washed three times for at least $2 \mathrm{~h}$ each with $1 \mathrm{X}$ TE prior to restriction digestion. They were incubated for $24 \mathrm{~h}$ at $25^{\circ} \mathrm{C}$ with $10 \mathrm{U}$ of $S m a \mathrm{I}$ in a $250 \mu \mathrm{l}$ solution consisting of the enzyme buffer and bovine serum albumin (Promega Corp., Madison, WI, USA) following manufacturer's recommendations for concentrations of each reagent. Digestion with other endonucleases was carried out in a similar manner, using buffers and temperatures recommended by the supplier.

\section{Pulsed-field gel electrophoresis}

Separation of DNA fragments was performed in a CHEF DRIII electrophoresis cell (Bio-Rad). Agarose gels were prepared using $1.2 \%$ pulsed-field running gel agarose (Sigma) in $0.5 \mathrm{X}$ TBE $\left(45 \mathrm{mmol} \mathrm{l}^{-1}\right.$ Tris, $45 \mathrm{mmol} \mathrm{l}^{-1}$ boric acid, $1 \mathrm{mmol} \mathrm{l}^{-1}$ EDTA, pH 8.0). Electrophoresis was performed at $8^{\circ} \mathrm{C}$ for $17 \mathrm{~h}$ at $6 \mathrm{~V} \mathrm{~cm}^{-1}$ at $120^{\circ}$ included angle with switching times of 1-20 s. These running conditions were optimized for the separation of
DNA fragments of $40-200 \mathrm{~kb}$. SmaI-digested DNA of L. gasseri ATCC 33323 was used as a standard. For each run, the standard was placed in the first, middle and last lane to allow alignment of the gel in the subsequent analysis of gel images. The standard was chosen based on: (i) good DNA quality, which would lead to discrete bands on the gel; (ii) sufficient amount of DNA, which would make the bands visible; and (iii) fairly even distribution of the bands on the gel. Gels were stained with ethidium bromide and photographed on a UV transilluminator.

\section{Data analysis}

Gel images were digitized with Gel Doc 1000 and Molecular Analyst Software version 1.4 (Bio-Rad). Normalization of densitometric traces with background subtraction and conversion were carried out with GelCompar version 4.2 (Applied Maths BVBA, Sint-Martens-Latem, Belgium). Clustering of strains was calculated using the unweighted pair group method with arithmetic averages (UPGMA). 


\section{RESULTS}

\section{Selection of restriction enzymes}

The restriction enzyme, $S m a$ I, was employed initially to digest DNA from 59 probiotic and research Lactobacillus and Bifidobacterium strains (Fig. 1). This enzyme, with the recognition sequence CCC/GGG, produced suitable PFGE patterns for most of the lactobacilli tested. However, for some probiotics such as L. paracasei and Bifidobacterium species that have greater frequencies of guanine and cytosine in their genome, SmaI cut the genomic DNA more extensively and the resulting patterns are difficult to visually evaluate. Consequently, several alternative restriction enzymes including $X b a \mathrm{I}, P s t, E c o \mathrm{RV}, X h o, N o t \mathrm{I}$ and $S f \mathrm{I}$ were tested. It was not possible to identify one restriction enzyme that was effective for all probiotic strains. Overall, we found that $S m a \mathrm{I}, N o t \mathrm{I}$ and $X b a \mathrm{I}$ could effectively generate clear and easy-to-interpret PFGE patterns of a range of probiotic strains.

\section{Evaluation of PFGE patterns}

Direct, visual comparisons of PFGE patterns revealed that many strains shared similar or identical patterns. Most of these strains fall into one of the following categories: (i) they were isolated from the same product (e.g. L. delbruecikk subsp. bulgaricus DPTC 020 and DPTC 021); (ii) they were isolated from different products belonging to the same company (e.g. L. paracasei DPTC 031, DPTC 32 and DPTC 036); (iii) they were provided by the same supplier, although some identical strains were given different strain designations (e.g. L. rhamnosus DPTC 043 and DPTC 044, L. crispatus DPTC 011 and DPTC 015); or (iv) they were obtained from different sources (e.g. L. acidophilus DPTC 005, DTPC 006 and ATCC 700396). In addition, evaluation of the PFGE patterns also suggests that the four $L$. reuteri strains produced distinctly different patterns. It is worth noting that, with the exception of ATCC 4356 and ATCC 700396, all reference (ATCC) strains showed distinct patterns compared with the commercial strains of the same species. This suggests that most commercial probiotic strains are markedly different from the reference strains.

\section{Cluster analysis}

Clustering of 59 probiotic strains cut with SmaI using UPGMA yielded three major groups of $>50 \%$ similarity (Fig. 1). The first group, with a similarity of $64 \cdot 8 \pm 4 \cdot 6 \%$, was composed mostly of $L$. delbrueckii subsp. bulgaricus (49-51 G + C mol\%; Kandler and Weiss 1986) and Bifidobacterium strains (55-67 G + C mol\%, Schleifer and Ludwig 1995). Group 2, with a similarity of
$68 \cdot 2 \pm 10 \cdot 2 \%$, contained mostly L. reuteri $(40-42 \mathrm{G}+\mathrm{C}$ $\mathrm{mol} \%)$, L. paracasei (45-47 G $+\mathrm{C} \mathrm{mol} \%$ ) and L. rhamnosus (45-47 G + C mol\%), with a few Bifidobacterium strains. Group 3, with a similarity of $52 \pm 11 \cdot 1 \%$, contained one $L$. paracasei strain and species from the $L$. acidophilus group, which comprises L. acidophilus (32-37 G + C $\mathrm{mol} \%)$, L. crispatus (35-38 G + C mol\%), L. gasseri (33$35 \mathrm{G}+\mathrm{C} \mathrm{mol} \%$ ), L. johnsonii and L. gallinarum. Clustering using the alternative Ward linkage method gave slightly different groupings (data not shown). Three major clusters were still identified, but at higher similarity levels. The main discrepancy between the Ward and the UPGMA methods was that L. johnsonii ATCC 33200 was placed in group 1 with the Ward method, instead of group 3 with the UPGMA method.

Among the three groups, SmaI-PFGE patterns of group 3 are the most distinct. The quantitative cluster analysis is largely consistent with the qualitative direct, visual evaluation. For instance, L. crispatus DPTC 010, DPTC 011, DPTC 012, DPTC 013, DPTC 014, DPTC 015 and DPTC 048 shared highly similar PFGE patterns upon direct, visual comparison. They also grouped together in the cluster analysis. Similarly, L. gasseri DPTC 025 and DPTC 049, which shared identical PFGE patterns, also clustered together. A notable exception is L. acidophilus DPTC 006, which had a similar pattern to L. acidophilus DTPC 007, ATCC 4356 and ATCC 700396 upon qualitative evaluation. These strains, however, did not cluster closely and had only $52 \%$ similarity. The low similarity score suggests that actual and substantial differences exist among these strains - as discussed below, these strains have different carbohydrate fermentation patterns. Alternatively, the low similarity score could also be the result of the strong band intensities of DPTC 006 that made the cluster analysis less accurate (the bands were discrete when seen on gel, but appeared to smear in print).

In contrast to the results of Ferrero et al. (1996), L. rhamnosus and $L$. paracasei could not be differentiated using SmaI. More distinct PFGE patterns for L. paracasei, $L$. rhamnosus and $L$. reuteri were generated using Not $\mathrm{I}$ (Fig. 2). On the basis of visual judgment, DPTC 033 and DPTC 030 had highly similar patterns, whereas DPTC 036, DPTC 031 and DPTC 032 shared identical patterns. Cluster analysis based on PFGE patterns confirmed the close relationship of each group. The similarity score of each group was $>97 \%$.

Similar analysis was also performed on Bifidiobacterium strains that were cut with $X b a \mathrm{I}$ (Fig. 3). Fourteen $X b a \mathrm{I}-$ digested Bifidobacterium strains were divided into five clusters at similarity levels of $>60 \%$. With the exception of the strains in the B. lactis cluster (DPTC 002, DPTC 003 and DPTC 047), all strains showed rather dissimilar PFGE patterns, implying that the strains were distinctly different. 


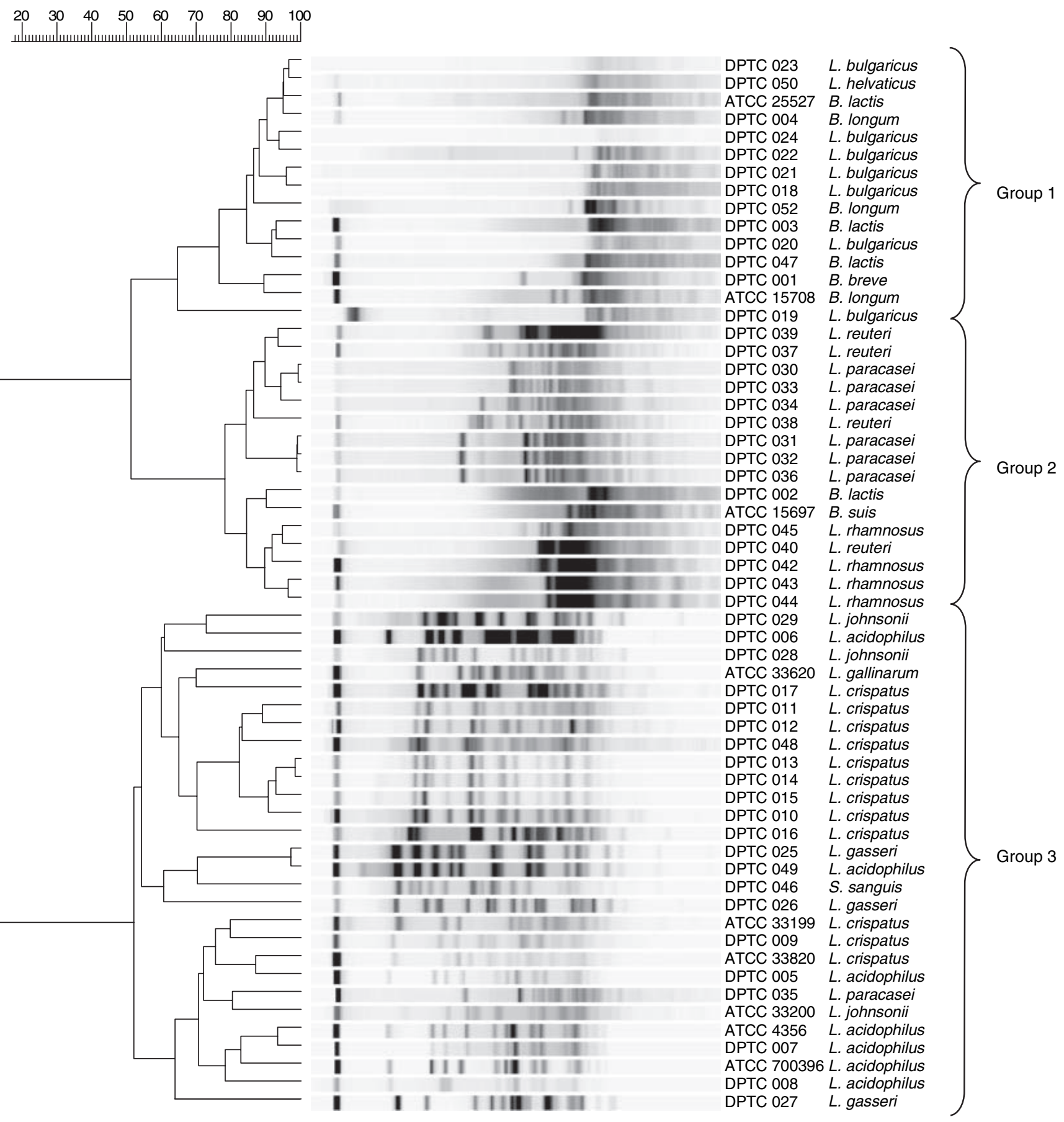

Fig. 1 Clustering of PFGE patterns following SmaI digestion using UPGMA method. Lactobacillus delbrueckii subsp. bulgaricus is abbreviated as L. bulgaricus

\section{Comparison between PFGE and phenotypic analysis}

As phenotypic expression of genes is more important to probiotic efficacy than DNA content, it is of interest to compare phenotypic with genotypic profiles. Strains used in this study had been previously characterized by carbohydrate fermentation analysis (Yeung et al. 2002). No correlation was found following comparison between the PFGE patterns determined in this study with the 
Fig. 2 Clustering, using UPGMA method, of PFGE patterns following $N o t$ digestion of Lactobacillus paracasei and L. rhamnosus strains

Fig. 3 Clustering, using UPGMA method, of PFGE patterns following $X b a \mathrm{I}$ digestion of Bifidobacterium strains
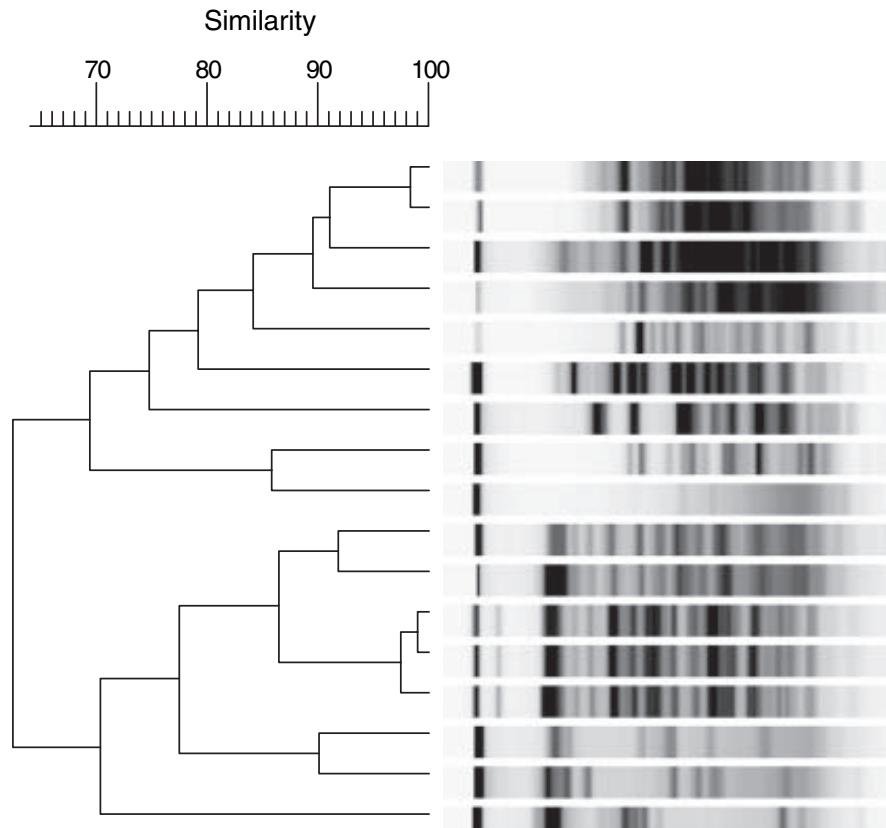

DPTC 033

DPTC 030

ATCC 53103

DPTC 043

ATCC 25302

DPTC 035

DPTC 034

DPTC 044

DPTC 039

DPTC 045

DPTC 042

DPTC 032

DPTC 036

DPTC 031

DPTC 038

DPTC 040

DPTC 037

Similarity
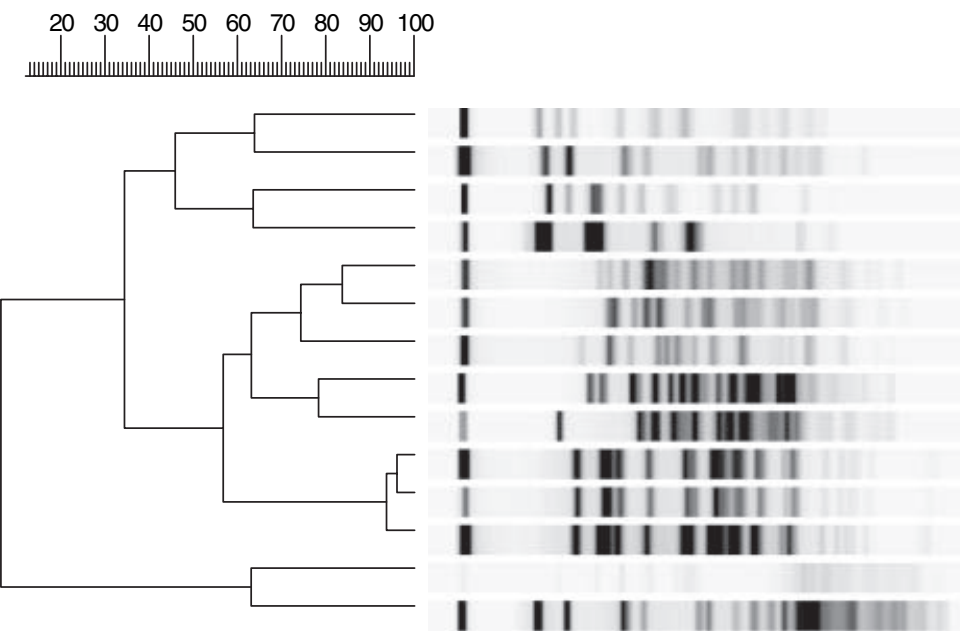

ATCC 15698

DPTC 001

ATCC 15696

ATCC 29521

DPTC 004

ATCC 15708

DPTC 052

ATCC 15697

ATCC 25962

DPTC 047

DPTC 003

DPTC 002

ATCC 25527

ATCC 15700 carbohydrate fermentation profiles. Some strains shown to be highly related by PFGE demonstrated identical carbohydrate fermentation profiles (Table 2), e.g. L. gasseri DPTC 025 and DPTC 049, and L. paracasei DPTC 031, DPTC 032 and DPTC 036. Different carbohydrate fermentation capability was evident for strains sharing high PFGE pattern similarity (e.g. L. paracasei DPTC 030 and DPTC 033). L. reuteri DPTC 039, DPTC 040 and ATCC 23272 appeared to have distinctly different PFGE patterns but shared identical carbohydrate fermentation profiles (data not shown). Finally, strains sharing less similar PFGE patterns (as indicated by generally $<90 \%$ similarity score in the cluster analysis) demonstrated distinctly different carbohydrate fermentation profiles. For example, PFGE patterns of $L$. acidophilus ATCC 4356 and DPTC 007 showed $c a 90 \%$ similarity by cluster analysis. This lower similarity score was consistent with their nonidentical carbohydrate fermentation profiles, in which ATCC 4356 did not ferment arbutine. Lactobacillus acidophilus DPTC 005, DPTC 006 and ATCC 700396 did not cluster closely with PFGE-generated data. Their phenotypic differences were apparent: ATCC 700396 fermented D-mannose while the other two did not; DPTC 005 fermented amygdaline and $\beta$-gentiobiose while the other two did not; and DPTC 006 did not ferment cellobiose while the other two did. 


\begin{tabular}{|c|c|c|c|}
\hline Genus species & Strain & $\begin{array}{l}\text { Similarity score (\%) } \\
\text { of PFGE patterns }\end{array}$ & $\begin{array}{l}\text { Carbohydrate } \\
\text { fermentation comments }\end{array}$ \\
\hline L. acidophilus & $\begin{array}{l}\text { DPTC } 005 \\
\text { DPTC } 006 \\
\text { DPTC } 007 \\
\text { ATCC } 4356 \\
\text { ATCC } 700396\end{array}$ & 52 & $\begin{array}{l}\text { ATCC } 4356 \text { and DPTC } 007 \text { galactose }^{-} \\
\text {DPTC } 005 \text { and DPTC } 006 \text { D-mannose } \\
\text { ATCC } 700396 \text { and DPTC } 006 \text { amygdaline }^{-} \\
\text {and } \beta \text {-gentiobiose } \\
\text { DPTC } 007 \text { arbutine }^{+} \\
\text {DPTC } 006 \text { cellobiose }\end{array}$ \\
\hline L. paracasei & $\begin{array}{l}\text { DPTC } 031 \\
\text { DPTC } 032 \\
\text { DPTC } 036\end{array}$ & $98 \cdot 8$ & Strains shared identical profiles \\
\hline L. paracasei & $\begin{array}{l}\text { DPTC } 030 \\
\text { DPTC } 033\end{array}$ & $99 \cdot 3$ & $\begin{array}{l}\text { DPTC } 033 \text { ribose }^{-} \\
\text {DPTC } 030 \text { amidon }^{-}\end{array}$ \\
\hline L. rhamnosus & $\begin{array}{l}\text { DPTC } 043 \\
\text { DPTC } 044\end{array}$ & 96 & $\begin{array}{l}\text { DPTC } 043 \text { dulcitol }^{-}, \text {amygdaline }^{-} \text {, } \\
\text { cellobiose }^{-}\end{array}$ \\
\hline$L$ gasseri & $\begin{array}{l}\text { DPTC } 025 \\
\text { DPTC } 049 *\end{array}$ & $97 \cdot 1$ & Strains shared identical profiles \\
\hline L. crispatus & $\begin{array}{l}\text { DPTC } 012 \\
\text { DPTC } 013 \\
\text { DPTC } 014 \\
\text { DPTC } 015 \\
\text { DPTC } 011\end{array}$ & $82 \cdot 2$ & $\begin{array}{l}\text { DPTC } 014 \text { and DPTC } 015 \text { D-fructose } \\
\text { DPTC } 012 \text { and DPTC } 013 \text { D-mannose } \\
\text { DPTC } 014 \text { N-acetyl glucosamine }^{-} \\
\text {DPTC } 013 \text { esculine }^{+}\end{array}$ \\
\hline L. rhamnosus & $\begin{array}{l}\text { DPTC } 042 \\
\text { DPTC } 045\end{array}$ & 92 & DPTC 042 inositol $^{-}$ \\
\hline
\end{tabular}

*Partial 16S rDNA sequencing data is not available for DPTC 049. This strain was identified as L. acidophilus by carbohydrate fermentation analysis. However, carbohydrate fermentation analysis could not differentiate L. acidophilus and L. gasseri (Yeung et al. 2002). This strain shared a highly similar PFGE pattern with L. gasseri DPTC 025 and thus is likely to be L. gasseri.
Table 2 Groupings of strains based on analysis of PFGE patterns and concomitant carbohydrate fermentation profiles

\section{DISCUSSION}

The ability to accurately differentiate among different strains of probiotic bacteria is important in the commercial application of probiotics. The strain-specific nature of functionality of different probiotic strains is suggested by the range of results generated on different strains in vitro (Lee et al. 1993; Gupta et al. 1996; Jacobsen et al. 1999), although few direct comparisons of strains for health effects have been conducted in humans. For this reason, it is important that probiotic products reveal the identity of specific strains on the labels. This practice would not only enable professionals to better evaluate the research base for substantiating a specific product's efficacy, but would also give emphasis to the importance of strain-specificity of health effects to consumers. Being able to conclusively identify strains in commercial probiotic products can be important if a product is suspected of contributing to an adverse incident in a consumer (Borriello et al. 2003). Finally, from the point of view of product manufacturers, using strain-specific patterns to verify phenotypic and genotypic consistency among production runs is a useful quality control technique. For these reasons it is critical that techniques such as PFGE become mainstream in the probiotic product industry.

The PFGE is a molecular strain-typing method that can be used in the identification of different strains within a species. Hence this method is useful in taxonomic grouping and epidemiological studies. PFGE not only plays an important role in foodborne outbreak investigations (http:// www.cdc.gov/pulsenet), it also has become integral in studying probiotic strain relatedness (Klein et al. 1998; Mitterdorfer et al. 2002). To illustrate, PFGE has been used to complement and confirm other strain-typing methods and to study the dynamics of indigenous lactic acid bacteria and bifidobacteria in human feeding studies (McCartney et al. 1996; Kimura et al. 1997). Results from previous studies support the notion that PFGE is a powerful strain-typing method because of its superior discriminatory power over other methods (Kimura et al. 1997; O'Riordan and Fitzgerald 1997; FAO/WHO 2002, ftp.fao.org/es/ESN/food/ foodandfood_probio_en.stm). However, the disadvantages of this method include its time-consuming nature (7-9 days) and the need to predetermine restriction enzymes which provide suitable fragment patterns.

In most cases, direct, visual evaluation of PFGE patterns among strains within the same species provides sufficient 
information for strain differentiation purposes. More recently, statistical methods have been developed to analyse the genotypic 'fingerprints' that include PFGE patterns. For example, cluster analysis on patterns generated from RAPDPCR and/or PFGE has been applied to probiotic lactobacilli (Roy et al. 2000) and Saccharomyces spp. (Mitterdorfer et al. 2002). Results from cluster analysis provide a quantitative measure that can be used to establish relatedness of a large number of strains. However, it is important to realize that PFGE is considered to be a strain- not a species-typing technique. To illustrate, taxonomically, L. delbrueckii subsp. bulgaricus strains are relatively distinct from the Bifidobactium species, yet they share relatively similar PFGE patterns following SmaI digestion, and are clustered together in Fig. 1. In this study, the aim of the cluster analysis is to provide an overview on the relatedness and grouping among various strains. To definitively determine the species taxonomy, and/or to construct phylogeny relationships, it is more appropriate to apply techniques such as $16 \mathrm{~S} \mathrm{rDNA}$ sequencing.

Our results confirm that important differences existed between genotype and phenotype. Thus, as suggested by Vandamme et al. (1996), a polyphasic approach, in which a combination of genotypic and phenotypic analyses are employed, is required to ultimately delineate bacterial taxonomy. Although it is understandable that no single method alone can provide the complete picture of a strain's identity, PFGE is still a useful strain-typing technique as it is discriminatory, and unlike carbohydrate fermentation and FAME analyses, the resulting patterns are not significantly affected by experimental conditions such as incubation temperature and/or incubation time.

In conclusion, PFGE and cluster analysis of a library of commercial and research strains allowed for clear strain identification and showed several levels of relatedness among the strains tested. This approach is valuable to the probiotic industry in developing commercial strain identification patterns, providing quality control of strain manufacturing production runs, tracking use of protected strains and determining the relatedness among different research and commercial probiotic strains.

\section{ACKNOWLEDGEMENTS}

This research was supported by California Dairy Research Foundation. The authors would like to acknowledge the many companies and research laboratories that kindly provided bacterial strains for this research, including T. R. Klaenhammer, North Carolina State University; G. Reid, University of Western Ontario; L. Peterson, formerly of Chr. Hansen, Inc.; S. Bush, Rhodia Inc.; S. Arnaldo, formerly of Institute Rosell; R. Zink, formerly of Nestlé; W. Sandine, formerly of Oregon State University; I. Casas, formerly of Biogaia Biologics; and H. Parsekian, Northeast Nutraceuticals. Technical advice provided by T. R. Klaenhammer and R. Jiménez-Flores is greatly appreciated.

\section{REFERENCES}

Borriello, S.P., Hammes, W.P., Holzapfel, W., Marteau, P., Schrezenmeir, J., Vaara, M. and Valtonen, V. (2003) Safety of probiotics that contain lactobacilli or bifidobacteria. Clinical and Infectious Disease 36, 775-780.

Bourget, N., Simonet, J.M. and Decaris, B. (1993) Analysis of the genome of the five Bifidobacterium breve strains: plasmid content, pulsed-field gel electrophoresis genome size estimation and $\mathrm{rrn}$ loci number. FEMS Microbiology Letters 110, 11-20.

Daniel, P. (1995) Sizing of the Lactobacillus plantarum genome and other lactic acid bacteria species by transverse alternating field electrophoresis. Current Microbiology 30, 243-246.

Ferrero, M., Cesena, C., Morelli, L., Scolari, G. and Vescovo, M. (1996) Molecular characterization of Lactobacillus casei strains. FEMS Microbiology Letters 140, 215-219.

Gupta, P.K., Mital, B.K. and Garg, S.K. (1996) Characterization of Lactobacillus acidophilus strains for use as dietary adjunct. International Journal of Food Microbiology 29, 105-109.

Hielm, S., Bjorkroth, J., Hyytia, E. and Korkeala, H. (1998) Genomic analysis of Clostridium botulinum group II by pulsed-field gel electrophoresis. Applied and Environmental Microbiology 64, 703-708.

Jacobsen, C.N., Nielsen, V.R., Hayford, A.E., Moller, P.L., Michaelsen, K.F., Paerregaard, A., Sandstrom, B., Tvede, M. et al. (1999) Screening of probiotic activities of forty-seven strains of Lactobacillus spp. by in vitro techniques and evaluation of the colonization ability of five selected strains in humans. Applied and Environmental Microbiology 65, 4949-4956.

Kandler, O., and Weiss, N. (1986) Genus Lactobacillus Beijerinck 1901, $212^{\mathrm{AL}}$. In Bergey's Manual of Systematic Bacteriology, Vol. 2. ed. Sneath, P.E., Mair, N.S. and Sharpe, M.E. pp. 1209-1234. Baltimore, MD: Williams \& Wilkins.

Kimura, K., McCartney, A.L., McConnell, M.A. and Tannock, G.W. (1997) Analysis of fecal populations of Bifidobacteria and Lactobacilli and investigation of the immunological responses of their human hosts to the predominant strains. Applied and Environmental Microbiology 63, 3394-3398.

Klein, G., Pack, A., Bonaparte, C. and Reuter, G. (1998) Taxonomy and physiology of probiotic lactic acid bacteria. International fournal of Food Microbiology 41, 103-125.

Leblond, P., Francou, F.X., Simonet, J.-M. and Decaris, B. (1990) Pulsed-field gel electrophoresis analysis of the genome of Streptomyces ambofaciens strains. FEMS Microbiology Letters 72, 79-88.

Lee, J., Ametani, A., Enomoto, A., Sato, Y., Motoshima, H., Ike, F. and Kaminogawa, S. (1993) Screening for the immunopotentiating activity of food microorganisms and enhancement of the immune response by Bifidobacterium adolescentis M101-4. Bioscience, Biotechnology, and Biochemistry 57, 2127-2132.

Marteau, P., Seksik, P. and Jian, R. (2002) Probiotics and health: new facts and ideas. Current Opinions in Biotechnology 13, 486-489.

McCartney, A.L., Wenzhi, W. and Tannock, G.W. (1996) Molecular analysis of the composition of the Bifidobacterial and Lactobacillus 
microflora of humans. Applied and Environmental Microbiology 62, 4608-4613

Mitterdorfer, G., Mayer, H.K., Kneifel, W. and Viernstein, H. (2002) Clustering of Saccharomyces boulardii strains within the species $S$. cerevisiae using molecular typing techniques. Fournal of Applied Microbiology 93, 521-530.

O'Riordan, K. and Fitzgerald, G.F. (1997) Determination of genetic diversity within the genus Bifidobacterium and estimation of chromosomal size. FEMS Microbiological Letters 156, 259-264.

O'Sullivan, D.J. (1999) Methods for analysis of the intestinal microflora. In Probiotics. A Critical Reviem ed. Tannock, G.W. pp. 23-44. Norfolk, UK: Horizon Scientific Press.

Rautio, M., Jousimies-Somer, H., Kauma, H., Peitarinen, I., Saxelin, M., Tynkkynen, S. and Koskela, M. (1999) Liver abscess due to a Lactobacillus rhamnosus strain indistinguishable from L. rhamnosus strain GG. Clinical and Infectious Disease 28, 1159-1160.

Roussel, Y., Colmin, C., Simonet, J.M. and Decaris, B. (1993) Strain characterization, genome size and plasmid content in the Lactobacillus acidophilus group (Hansen and Mocquot). Journal of Applied Bacteriology 74, 549-556.

Roy, D., Ward, P., Vincent, D. and Mondou, F. (2000) Molecular identification of potentially probiotic lactobacilli. Current Microbio$\log y$ 40, 40-46.
Sanders, M.E., Walker, D.C., Walker, K.M., Aoyama, K. and Klaenhammer, T.R. (1996) Performance of commercial cultures in fluid milk applications. Fournal of Dairy Science 79, 943-955.

Schiffrin, E.J. and Blum, S. (2001) Food processing: probiotic microorganisms for beneficial foods. Current Opinions in Biotechno$\log y$ 12, 499-502.

Schleifer, K.H. and Ludwig, W. (1995) Phylogenetic relationships of lactic acid bacteria. In The Genera of Lactic Acid Bacteria ed. Wood, B.J.B. and Holzapfel, W.H. pp. 7-18. London: Blackie Academic and Professional.

Tanskanen, E.I., Tulloch, D.L., Hillier, A. and Davidson, B.E. (1990) Pulsed-field gel electrophoresis of SmaI digests of lactococcal genomic DNA, a novel method of strain identification. Applied and Environmental Microbiology 56, 3105-3111.

Vandamme, P., Pot, B., Gillus, M., Vos, P.D., Kersters, K. and Swings, J. (1996) Polyphasic taxonomy, a consensus approach to bacterial systematics. Microbiological Reviems 60, 407-438.

Yeung, P.S.M., Sanders, M.E., Kitts, C.L., Cano, R. and Tong, P.S. (2002) Species-specific identification of commercial probiotic strains. Journal of Dairy Science 85, 1039-1051. 